\title{
LGBT Community, Social Network Characteristics, and Smoking Behaviors in Young Sexual Minority Women
}

\author{
Michelle Marie Johns • Emily S. Pingel • \\ Emily J. Youatt · Jorge H. Soler • Sara I. McClelland • \\ Jose A. Bauermeister
}

Published online: 20 June 2013

(c) Society for Community Research and Action 2013

\begin{abstract}
Smoking rates among young sexual minority women (YSMW) are disproportionately high as compared to heterosexual populations. While this disparity has commonly been attributed to the sexual minority stress process, little empirical work has explored what may protect YSMW from high rates of smoking. Using data $(\mathrm{N}=471)$ from a crosssectional study designed to investigate YSMW's (age 18-24) smoking behaviors and correlates; we explore the relationship of LGBT community connections, YSMW's social network characteristics, and stress to smoking behaviors (i.e., status, frequency, amount). Through this analysis, we find support for LGBT community connection as well as friendships with other sexual minorities as protective in relation to YSMW's smoking behaviors. We discuss the implications of our results, highlighting the need for future longitudinal research and interventions designed to bolster YSMW's connections to the LGBT community and their social networks.
\end{abstract}

Keywords Smoking - Substance use - LGBT community · Participation - Social support - Sexual minority women .

Emerging adulthood

\section{Introduction}

Young sexual minority women (YSMW) use cigarettes at a disproportionately higher rate than heterosexual peers and

M. M. Johns $(\bowtie) \cdot$ E. S. Pingel · E. J. Youatt .

J. H. Soler - J. A. Bauermeister

Center for Sexuality and Health Disparities, School of Public

Health, University of Michigan, Ann Arbor, MI, USA

e-mail: johnsmm@umich.edu

S. I. McClelland

Psychology and Women's Studies, University of Michigan, Ann

Arbor, MI, USA are more likely to smoke than older sexual minority women (Blosnich et al. 2010; Brewster and Tillman 2012; Marshal et al. 2009, 2012; Pizacani et al. 2009). During adolescence and into young adulthood, sexual minority women report more use of cigarettes and take up cigarette smoking at a higher rate than heterosexual young women, increasing the size of the smoking disparity over time (Marshal et al. 2012). Furthermore, SMW appear to smoke at rates higher than sexual minority men, suggesting that there may be important gender difference in the risks of and protections against smoking among sexual minorities (Austin et al. 2004; Rosario 2008; Tang et al. 2004). This trend among YSMW is particularly alarming given the known risks of lung cancer associated with smoking, as well as increased risks for other cancers such as cervical, which affect more SMW than heterosexual women (Brown and Tracy 2008; CDC 2012). Consequently, YSMW are a priority group for smokingrelated research and interventions. Although prior research notes the connection between smoking and sexual minority stress in sexual minority women (Gruskin et al. 2008), less is known about how community and social relationships (e.g., connection to the LGBT community, having friends of the same identity) relate to the smoking behaviors of this population. Understanding how YSMW's connections to the LGBT community and other identity-based supports relate to their smoking behaviors is critical towards developing multilevel smoking interventions with YSMW.

\section{The LGBT Community}

The term LGBT community refers to the collective identity constructed around the social and relational ties between people who are sexual (lesbian, gay, bisexual) and/or gender (transgender) minorities (Ferris 2006). The LGBT community operates at many levels: nationally, through 
political organizing for legal rights of sexual minorities (e.g., marriage equality, adoption rights) or in media representations of gay and lesbian characters in television and movies, and locally, through presence of LGBT neighborhoods in metropolitan areas or social venues like restaurants or bars catering to LGBT clientele (Ferris 2006). Researchers have examined whether feelings of connectedness to an LGBT community have health protective features, and theorize that involvement with other sexual minorities may be useful in establishing comfort or pride in one's sexual identity as well as in forging connections between people experiencing similar social challenges (Frost and Meyer 2012; Ramirez-Valles 2002; Rosario et al. 2001). Indeed Kertzner et al. (2009) found that sexual minorities who reported higher levels of LGBT community connectedness (i.e., a feeling of belonging to a greater community of identity) also possessed an increased sense of social and psychological wellbeing, thus presenting connections to the LGBT community as having the protective benefits for sexual minorities. Similarly, work on the coming out process of sexual minority adolescents finds that engaging with gay and lesbian community events may be psychologically protective during those formative years (Rosario et al. 2001). For this reason, we were particularly interested in the relationship of LGBT community connections to smoking for YSMW to investigate whether the community offered an area of protection or risk for young women.

On one hand, LGBT community connections may be health protective. Forging connections with the LGBT community may buffer against the effects of sexual minority stress (Meyer 2003), and reduce the need for YSMW to smoke as a coping mechanism. SMW cite community connections as integral to combating seclusion that might otherwise be experienced as a sexual minority living in a heterosexist society (Lehavot et al. 2009). Research has demonstrated that access to a visible LGBT community may reduce sexual minority youth's likelihood of smoking. Indeed, one study found that living in a climate supportive of sexual minorities (i.e., high density of same sex couples, proportion of schools with gay-straight alliances, proportion of schools with anti-bulling and antidiscrimination policies focused on sexual orientation) was linked to lower smoking rates among adolescents (Hatzenbuehler et al. 2011). Alternatively, some researchers interested in participation in the LGBT community find evidence for the opposite effect of community ties on smoking behaviors: community participation may promote smoking. In focus group research with LGBT youth (age 18-24), participants discussed smoking as a social activity that was inherent to the LGBT community and that by smoking they forged connections with other sexual minority youth (National LGBTQ Young Adult Tobacco
Project 2010). Synthesizing both of these results, Rosario and colleagues (2004) found during the coming out process, youth's participation in LGBT community activities was associated with an initial uptick in substance use (including tobacco), but over time, continued participations was associated with decreased use. With this complex picture of the role of LGBT community in predicting substance use among YSMW, further research is warranted.

\section{Social Network Characteristics}

The LGBT community is heterogeneous in its makeup, containing people of various social identities (i.e., sexual identity, gender, race/ethnicity, class background), each who may have different experiences relating to LGBT community spaces (Ferris 2006; Frost and Meyer 2012). Historically, due to funding structures tied up in HIV prevention and treatment, community-based organizations that serve LGBT people and shape local LGBT communities of identity have emphasized the needs of sexual minority men over those of sexual minority women (Ward 2008). As such, YSMW may not readily identify with LGBT venues such as organizations and bars that are traditionally thought of as meeting spaces for all sexual minorities. As reflected in the discussion of LGBT community and health above, access to identity affirming spaces and communities may have real health benefits for sexual minorities. Given that LGBT community spaces may not be as accessible to young women as they are to young men, investigations into the ways that YSMW interact with other sexual minorities may need to consider constructs beyond LGBT community. By examining the characteristics of YSMW's social networks, researchers may be able to assess whether YSMW have connections to other sexual minorities outside of these LGBT community contexts.

Broadly, social networks (i.e., an individual's interpersonal connections to other people) have been closely linked to health outcomes (Heaney and Israel 2002). Alongside the structural properties of social networks (e.g., size and density), Heaney and Israel (2002) characterize networks by their interactional (i.e., nature of the relationships in the network; e.g., shared traits or homophily between network members and the frequency of their interactions) and functional (i.e., the interpersonal sharing of aid and resources; e.g., social support) properties. With regard to YSMW, a health promotive social network must have relationships that support and affirm women's sexual minority identities in order to offset sexual minority stress (Nuttbrock et al. 2002; Doty et al. 2010). Research with LGB youth and adults has demonstrated that the presence of sexuality-specific support in social networks improves mental health, an outcome that has been linked to the 
sexual minority stress process (Beals and Peplau 2005, Doty et al. 2010, Meyer 2003). In a sample of LGB youths, (Rosario et al. 2011) found that social support buffered the relationship between smoking and mental distress, reducing the reported levels of mental distress most clearly in smokers. In that respect, social networks may have serious implications for the coping strategies YSMW use, and thus their likelihood of smoking.

Despite the promising nature of these results, little comprehensive work testing the relationship of social network characteristics on YSMW's likelihood of smoking exists. If the pattern of risk reduction for smoking mirrors that which has been identified among social support and other minoritystress related outcomes, possessing identity-affirming social networks may reduce YSMW's likelihood of smoking. Conversely, given the higher incidence of smoking behaviors in sexual minority populations (Blosnich et al. 2010; Marshal et al. 2009; Pizacani et al. 2009), and given the broader smoking literature pointing to social network norms around tobacco use being highly predictive of an individual's use of tobacco products (Christakis and Fowler 2008), YSMW who find identity affirmation by socializing with other sexual minority women may, in fact, increase their likelihood of smoking, regardless of any reduction of stress. The direction and strength of these relationships between social network characteristics and smoking behaviors among YSMW remain an untested area that the current study seeks to address.

\section{Smoking Behaviors}

The bulk of research on smoking among YSMW evaluates smoking behavior as a binary indicator: women are either smokers or non-smokers (Blosnich et al. 2011; Hatzenbuehler et al. 2011, Marshal et al. 2009). While a binary approach is useful for the examination of disparities in the prevalence of cigarette smoking across populations of youth, when exploring the psychosocial mechanisms behind YSMW's tobacco use, this approach may be reductive. For example, smoking literature highlights that motivations for smoking may differ significantly between those who are heavy smokers (daily, $5+$ cigarettes) and those who are light smokers or chippers (less than daily, $<5$ cigarettes) (Okuyemi et al. 2002). The smoking literature is clear to distinguish between these two groups, for heavy smokers appear to be more likely to smoke due to a chemical dependence on nicotine, while light smokers appear to be less physically dependent (Okuyemi et al. 2002; Shiffman 1989; Wellman et al. 2006). Indeed, light smokers or chippers are more apt to cite social reasons for smoking, such as party attendance or feelings of stress, suggesting the psychosocial mechanisms that facilitate the smoking behaviors of light smokers may be different than those of heavy smokers (Okuyemi et al. 2002). Given our focus on how social dynamics relate to the smoking behaviors of YSMW, a more detailed examination of YSMW's types of smoking behavior is needed.

\section{The Current Study}

The relationship between community connections, social network characteristics, stress, and types of smoking behaviors of YSMW has yet to be adequately evaluated. In order to build efficacious and appropriate smoking interventions for YSMW, it is imperative to investigate how LGBT community connection and social network characteristics relate to smoking behaviors broadly (i.e., smokers versus non-smokers) in the face of generalized and sexual minority stress, as well as how these factors connect (or do not) to within group differences among smokers (i.e., how frequently women smoke, how much they smoke). As such, we aim to address the following research questions in this study:

1. How do YSMW's experiences of generalized and sexual minority stress relate to their smoking behaviors (i.e., status, frequency, amount)?

2. How do YSMW's participation in the LGBT community relate to their smoking behaviors (i.e., status, frequency, amount)?

3. How do the characteristics of YSMW's social networks relate to their smoking behaviors (i.e., status, frequency, amount)?

4. Does the relationship between LGBT community participation and YSMW's smoking behaviors operate independently from the relationship between their social network characteristics and smoking behaviors?

\section{Methods}

Sample

The current study used data from the Michigan Smoking and Sexuality Survey (M-SASS), a cross-sectional, observational study examining young sexual minority women and their smoking behaviors conducted in the summer of 2011 (analytic sample size $\mathrm{n}=471$ ). Women in this study ranged in age from 18 to 24 with a mean age of 21.41 $(\mathrm{SD}=1.79)$. We recruited women who identified as sexual minorities or had sexual experiences with a woman in the past year. When asked to report on their sexual identity, $55 \%$ of women in this sample identified as lesbian, $33 \%$ as bisexual, and $13 \%$ as some other identity (i.e., queer, pansexual, no label, heterosexual). In terms of 
demographic composition of the sample, $70 \%$ identified their race or ethnicity as White/European-American, $11 \%$ identified as Black/African American, $6 \%$ as Latino/Hispanic, and $12 \%$ identified as some other racial category. Our sample contained geographical diversity. While we focused recruitment efforts on women currently residing in Michigan, our study did not require Michigan residence to participate, and thus our final sample was national (Michigan $n=224$, National $n=247$ ). Additionally, we asked women to characterize the area or neighborhood in which they lived-54\% reported they lived in an urban environment, $25 \%$ said suburban, $19 \%$ said rural, and $3 \%$ said other. The sample had diversity in the degree to which family and friends knew participants' sexual identities: $48 \%$ reported they were out to their mother, $33 \%$ out to their father, and $85 \%$ out to their friends. In terms of smoking behaviors, $25 \%$ of the sample identified as everyday smokers, $51 \%$ said they smoked some days, and $24 \%$ said they never smoked. Of the smokers $(n=360)$, $77 \%$ percent said they smoked five or more cigarettes a day (i.e., heavy smokers), while $23 \%$ said they smoked less than five cigarettes a day (i.e., light smokers). For a breakdown of relevant sociodemographic characteristics of this sample by smoking status, please see Table 1 .
Table 1 Descriptive Statistics by Smoking Status
Table presents mean values of scales in original metric; however, standardized ( $\mathrm{z}$ scored) versions of stress, social participation, and peer support are used in all regression models

\begin{tabular}{|c|c|c|c|c|}
\hline & \multicolumn{4}{|c|}{ Smoking frequency } \\
\hline & $\begin{array}{l}\text { Total sample } \\
(\mathrm{N}=471)\end{array}$ & $\begin{array}{l}\text { Everyday } \\
(\mathrm{n}=119)\end{array}$ & $\begin{array}{l}\text { Some days } \\
(\mathrm{n}=241)\end{array}$ & $\begin{array}{l}\text { Non-smoker } \\
(\mathrm{n}=111)\end{array}$ \\
\hline Sexual identity & $\#(\%)$ & $\#(\%)$ & $\#(\%)$ & $\#(\%)$ \\
\hline Lesbian & $258(54.78)$ & $57(47.90)$ & 159 (65.98) & $42(37.84)$ \\
\hline Bisexual & $154(32.70)$ & $47(39.50)$ & $70(29.05)$ & $35(31.53)$ \\
\hline Other & $59(12.53)$ & $15(12.61)$ & $10(4.15)$ & $34(30.63)$ \\
\hline \multicolumn{5}{|l|}{ Race/ethnicity } \\
\hline $\begin{array}{l}\text { White/European } \\
\text { American }\end{array}$ & $330(70.21)$ & $83(69.75)$ & $160(66.39)$ & $87(78.38)$ \\
\hline Black/African American & $54(11.49)$ & $11(9.24)$ & $38(15.77)$ & $5(4.50)$ \\
\hline Latino/Hispanic & $29(6.17)$ & $8(6.72)$ & $19(7.88)$ & $2(1.80)$ \\
\hline Asian/Pacific Islander & $8(1.70)$ & $1(0.84)$ & $6(2.49)$ & $1(0.90)$ \\
\hline Native American & $15(3.19)$ & $11(9.24)$ & $3(1.24)$ & $1(0.90)$ \\
\hline Other & $34(7.23)$ & $5(4.20)$ & $15(6.22)$ & $14(12.61)$ \\
\hline \multicolumn{5}{|l|}{ Neighborhood } \\
\hline Urban & $253(53.72)$ & $60(50.42)$ & $151(62.66)$ & $42(37.84)$ \\
\hline Suburban & $116(24.63)$ & $26(21.85)$ & $47(19.50)$ & $43(38.74)$ \\
\hline Rural & $90(19.11)$ & $29(24.27)$ & $41(17.01)$ & $20(18.02)$ \\
\hline Other & $12(2.55)$ & $4(3.36)$ & $2(0.83)$ & $6(5.41)$ \\
\hline \multicolumn{5}{|l|}{ Smoking intensity } \\
\hline $\begin{array}{l}\text { Light smokers ( }<5 \text { cigs/ } \\
\text { day) }\end{array}$ & $84(23.33)$ & $5(4.20)$ & $79(32.78)$ & - \\
\hline \multirow{2}{*}{$\begin{array}{l}\text { Heavy smokers ( } \geq 5 \text { cigs/ } \\
\text { day) }\end{array}$} & $276(76.67)$ & $114(95.80)$ & $162(67.22)$ & - \\
\hline & $\bar{x}(\mathrm{sd})$ & $\bar{x}(\mathrm{sd})$ & $\bar{x}(\mathrm{sd})$ & $\bar{x}(\mathrm{sd})$ \\
\hline Age & $21.41(1.79)$ & $21.69(1.76)$ & $21.56(1.61)$ & $20.77(2.02)$ \\
\hline Stress & $3.05(0.76)$ & $3.16(0.86)$ & $3.05(0.63)$ & $2.93(0.90)$ \\
\hline Discrimination (30 days) & $0.77(1.54)$ & $1.13(1.99)$ & $0.51(1.06)$ & $0.95(1.75)$ \\
\hline \multicolumn{5}{|l|}{ LGBT community } \\
\hline Connectedness & $1.18(0.87)$ & $1.05(0.82)$ & $1.22(0.81)$ & $1.24(1.00)$ \\
\hline $\begin{array}{l}\text { Organizational } \\
\text { membership }\end{array}$ & $0.87(0.82)$ & $0.71(0.81)$ & $1.06(0.80)$ & $0.61(0.76)$ \\
\hline Social participation & $2.24(0.95)$ & $2.13(0.97)$ & $2.36(0.85)$ & $2.10(1.09)$ \\
\hline \multicolumn{5}{|l|}{ Social networks } \\
\hline Peer support & $3.59(0.86)$ & $3.74(0.86)$ & $3.36(0.73)$ & $3.94(0.97)$ \\
\hline Friends of same identity & $1.53(0.74)$ & $1.48(0.80)$ & $1.58(0.69)$ & $1.48(0.77)$ \\
\hline Time with SSA women & $1.45(0.72)$ & $1.47(0.76)$ & $1.40(0.60)$ & $1.53(0.90)$ \\
\hline
\end{tabular}


Procedure

To be eligible for participation, recruits had to be between the ages of 18 and 24 (i.e., born between 1987 and 1993) and either identify as any sexual identity other than heterosexual or replied yes to a single item that asked if they had any sexual experiences with a woman in the past year. We recruited a convenience sample of participants through advertisements on Facebook, a social network site which allowed for our study advertisements to be displayed only to those women who identified themselves as between the ages of 18 and 24 and romantically interested in women (or women and men). Use of social networks for recruitment of young sexual minorities is common, and provides a mechanism for reaching out to sexual minorities who might not frequent LGBT-specific venues, either offline or online (Bauermeister 2012). All promotional materials displayed a synopsis of eligibility criteria, a mention of a $\$ 25$ electronic gift card incentive, and the survey's website.

For participant privacy, all study data were protected with a 128-bit SSL encryption and kept within a University of Michigan firewalled server. Upon entering the study site, participants were asked to enter a valid and private email address, which served as their survey username. This allowed participants to save their answers and complete their survey in more than one sitting if necessary. Participants were asked eight questions to determine their eligibility. If eligible, participants read a detailed consent form that explained the purpose of the study (i.e., exploring how YSMW choose whether or not to smoke cigarettes) and their rights as participants. YSMW were asked to acknowledge that they read and understood each section of the consent form (i.e., participation involvement, protection of privacy, uses of data, potential benefit, compensation, terms of the Certificate of Confidentiality, and who to contact if they had questions). Consented participants completed a 45-60 min survey covering topics such as sociodemographic characteristics, smoking attitudes and behaviors, alcohol and drug (AOD) use, sexuality, discrimination, and psychosocial wellbeing. Upon completing the survey, participants received an email from the University of Michigan containing a link to a secured CitiBank website that provided them with a credit card number good for $\$ 25$. If the participants chose, for a small fee (deducted from the \$25), the incentive could be deposited directly into their bank account or a printed gift card could be mailed to their home address. Within the final dataset, we removed duplicates and falsified entries by examining participants' email and IP addresses from the final sample, using best practices for web-based research (Bauermeister et al. 2012). Study data was protected by a Certificate of Confidentiality. All study procedures were approved by the Institutional Review Board of the University of Michigan, Ann Arbor.
Measures

\section{Demographics}

Participants were asked a series of questions about their sociodemographic characteristics, including their sexual identity. From these responses, we grouped women into three categories: lesbians, bisexual women, and other sexual identities. In all analyses, lesbians served as the referent group. Additionally, we asked women to specify their racial/ ethnic identity. Because the sample was predominantly White/European-American identified (70 \%), we treated race/ethnicity as a dummy variable with White/EuropeanAmerican as the referent group. To gauge the effects of participants' regional contexts, we asked participants "how would you characterize the area where you live?" Response options for this question were urban, rural, suburban, and other. For the analyses, this question was also recoded into a dummy variable where urban was 1 and all other area descriptors were 0. Lastly, we asked women their age, which we entered into the model as a continuous variable.

\section{Stress}

To measure stress, participants were asked to complete a daily hassles and control scale (Cohen et al. 1983). For the current study, we analyzed the 5-item daily hassles subscale that asked participants about experiences of stress over the past month (e.g., "how often have you found that you could not deal with all the things that you had to do?" and "how often have you been upset because of something that happened that you didn't expect?"), and had them rate the frequency with which participants agreed with these prompts on a scale from 1 (Never) to 5 (Very often). Items were mean scored to create a composite measure for use as a predictor $(\alpha=0.75)$, where high values signified higher levels of stress.

\section{Discrimination}

To assess discrimination related to sexual orientation (an experience of minority stress), we used a measure created by Meyer et al. (2006), which adapted scales of experiences of racial discrimination to include the experiences of all minority groups, including sexual minorities. In the web survey, we provided women with a checklist of experiences of mistreatment and discrimination (e.g., "been treated with less respect than others," and "been called names or insulted"), and asked them to check off those that they had experienced in the past 30 days. For every type of discrimination they checked, we prompted them with a follow up question, "do you think your experience of [type of discrimination] was related to your..." with response options indicating several social identities: gender, race/ 
ethnicity, sexual orientation, age, religion, physical appearance, income level/social class, other. Women could check off more than one identity as being a potential cause for their experience of discrimination. For this study, we created a variable of the total number of experiences of discrimination related to sexual orientation a woman reported in the past 30 days. If a participant did not report any such experiences, she received a 0 on this item. The final scores on this variable ranged from 0 to 9 .

\section{LGBT Community}

All the M-SASS LGBT community measures were adapted from a longitudinal survey of LGBT youth and psychosocial wellbeing (Bauermeister et al. 2010), and amended with data gathered during the qualitative arm of the study (Pingel et al. 2012; Youatt et al. 2012).

Connectedness To assess the degree to which women perceived themselves as part of a LGBT community, we used a single item: "How much do you see yourself personally as being part of the local (in your area) LGBTQ community?" Women could answer not at all, a little, some, or a lot. We treated this variable as continuous from 0 (Not at all) to 3 (A lot).

Organizational Membership To assess the degree to which women involved themselves in local LGBT community spaces, we asked women, "In this last year, how many local (in your area) LGBTQ organizations have you belonged to?" Response format was open, and participants could enter any number from 0 to 99 . Responses ranged from 0 to 10 , but given the negative skew of women's answers, we recoded this variable as continuous where $0=0,1=1$, and $2=2+$ organizations.

Participation Participants answered several questions about their participation in LGBT community activities in the past year. We extracted three questions which assessed level of social involvement in the LGBT community: (1) "did you attend programs at a LGBTQ organization," (2) did you go to LGBTQ social events (parties, dances, Pride)," and (3) "have you gone to a LGBTQ bar or club." Respondents could choose from six response options ranging from 1 (Never) to 6 (Once a week or more). A composite measure was created by mean scoring participants' responses on these three items $(\alpha=0.79)$, with higher scores indicating higher degrees of LGBT community participation.

\section{Social Network Characteristics}

Consistent with Heaney and Israel (2002), we assessed women's perceptions of the functional (e.g., peer support) and interactional (e.g., homophily by sexual identity and frequency of interaction) properties of their social networks.

Peer Support We captured general peer support using five items adapted from the Perceived Social Support from Friends Scale (PSS-Fr; Procidano and Heller 1983). Items in this scale addressed the quality of individuals' relationships with friends (e. g., "I rely on my friends for emotional support"). Items were answered on a 5-point scale from 1 (Not true) to 5 (Very true). We calculated a mean score for peer support-higher scores indicated more peer support $(\alpha=0.92)$.

Friends of the Same Sexual Identity To assess the homogeneity of women's social networks by sexual identity, women were asked, "In general, how many of your friends are of your same sexual orientation?" Response options were almost all of them, some of them, a few of them, and none of them. This item was developed out of qualitative interviews with YSMW in Phase I of the M-SASS project, which indicated that YSMW had social networks diverse in sexual identity. Thus, the anchor all was not included as a response option. Data collection validated this point, as the majority of women listed themselves as having some or a few friends of the same sexual identity. In the regression models, this variable was treated as continuous from 0 (None of them) to 3 (Almost all of them).

Time Spent with Same Sex Attracted Women To assess the frequency with which women interacted with other sexual minority women, we used an item developed out of earlier qualitative interviews with women about smoking and social relationships, "How much of your leisure time do you spend with same sex attracted women?" Response options were none, a little, some and a lot. In all regression models, the variable was treated as continuous from 0 (None) to 3 (A lot).

\section{Smoking}

Survey respondents answered several questions about their smoking behaviors. We asked women, "Do you now smoke cigarettes every day, some days, or not at all?" From how participants answered this question, we categorized women as either smokers (i.e., every day, some days) or non-smokers (i.e., not at all). In subsequent analyses on smokers only, we further differentiated between everyday and some days smokers. Women also answered the question, "Do you currently smoke at least 5 cigarettes a day (on most days of the week)?" We then categorized participants as either light smokers (i.e., women who smoke $<5$ cigarettes a day) or heavy smokers (i.e., women who smoke $\geq 5$ cigarettes a day). 
Data Analytic Strategy

To address our research questions of interest, we used a series of stepwise, logistic regressions on three dependent variables: (1) smoking status (i.e., smoker versus non-smoker), (2) smoking frequency (i.e., everyday versus some days), and (3) smoking amount (i.e., heavy smokers versus light smokers). We began with our binary smoking outcome in order to situate our findings within the broader conversation around smoking among sexual minorities, and then expanded our analyses to look at within smoker variation (frequency, amount) in order to move forward this line of research. Logistic regression provided a mechanism for examining to what degree a woman's characteristics predicted her smoking behaviors. For each smoking outcome, Model 1 included sociodemographic variables and LGBT community variables, and Model 2 included sociodemographic variables, LGBT community variables, and social network characteristic variables. In this way, we were able to examine whether the relationships between community predictors and smoking outcomes operated independently from social network characteristics, or if these relationships could be explained through social network characteristics. In all models, we controlled for the relationship of generalized and minority stress and smoking behaviors, as they have been clearly linked to smoking in general and LGBT samples (Bergen and Caporaso 1999; Gruskin et al. 2008). Finally, we also considered whether experiences of minority stress could moderate the relationships between community connections and smoking behaviors. These interaction models were not statistically significant (data not shown). Therefore, we present only main effects models.

\section{Results}

Stress and Smoking Behaviors

\section{Smokers Versus Nonsmokers}

Generalized stress was associated with an increased likelihood of being a smoker. In Model 1 (Demographics and LGBT Community Participation), a one standard deviation increase in generalized stress was associated with a $31 \%$ increased odds of being a smoker as compared to a nonsmoker. In Model 2 (Demographics, LGBT Community Participation, and Social Network Characteristics) this relationship remained significant, with a $29 \%$ increased odds of being a smoker as compared to being a non-smoker associated with a standard deviation increase in generalized stress. Experiences of discrimination, our proxy for minority stress, was unrelated to smoking status. For all results, see Table 2.
Everyday Smokers Versus Some Days Smokers

In examining the relationship of stress to the frequency of smoking in our sample, generalized stress was not associated with the likelihood of being an everyday smoker as compared to being a some days smoker. Conversely, experiences of discrimination were related to frequency of smoking. Within Model 1, each additional discriminatory event reported by participants was associated with an $8 \%$ increased odds of being an everyday smoker as compared to a some days smoker. This relationship was maintained after social network characteristics were introduced into the model, and each discriminatory event was associated with a 1.06 odds increase of being an everyday smoker as compared to a some days smoker. For full results, see Table 3.

\section{Heavy Smokers ( $\geq 5$ cigarettes per day) Versus Light Smokers $(<5$ cigarettes per day)}

We also examined the relationship of stress to the amount of cigarettes consumed by smokers in our sample. Across both Model 1 and Model 2, we found no association between amount of smoking and generalized stress or experiences of discrimination (see Table 4).

\section{LGBT Community Participation and Smoking Behaviors}

\section{Smokers Versus Nonsmokers}

Connection to the local LGBT community was associated with a reduced likelihood of being a smoker. On average, a one point increase on the connectedness item was associated with a $33 \%$ reduced odds of being a smoker as compared to being a non-smoker. Conversely, organizational membership was associated with increased odds of being a smoker. A one point increase on the organizational membership item was associated with a 1.67 odds increase of being a smoker as compared to being a nonsmoker. This finding indicates there may be a distinction between connectedness and membership in LGBT groups. There was no relationship between the social participation in the LGBT community scale and smoking status. For full results, see Model 1 in Table 2.

\section{Everyday Smokers Versus Some Days Smokers}

Among smokers $(\mathrm{n}=360)$, LGBT community participation was not influential in any direction, either protective or deleterious. A marginal association between LGBT organizational membership and a reduced odds of being an 
Table 2 Smokers versus Non-smokers ${ }^{\mathrm{a}}(\mathrm{N}=471)$

\begin{tabular}{|c|c|c|c|c|c|c|c|c|c|c|}
\hline \multirow[t]{2}{*}{ Variable } & \multicolumn{5}{|l|}{ Model 1} & \multicolumn{5}{|l|}{ Model 2} \\
\hline & Coefficient & $\begin{array}{l}\text { Standard } \\
\text { error }\end{array}$ & $\begin{array}{l}\text { Odds } \\
\text { ratio }\end{array}$ & $\begin{array}{l}\text { OR } \\
95 \%\end{array}$ & $\mathrm{CI}$ & Coefficient & $\begin{array}{l}\text { Standard } \\
\text { error }\end{array}$ & $\begin{array}{l}\text { Odds } \\
\text { ratio }\end{array}$ & $\begin{array}{l}\text { OR } \\
95 \%\end{array}$ & $\mathrm{CI}$ \\
\hline \multicolumn{11}{|l|}{ Sexual identity ${ }^{\mathrm{b}}$} \\
\hline Bisexual & -0.26 & 0.29 & 0.77 & 0.44 & 1.35 & -0.21 & 0.29 & 0.81 & 0.46 & 1.44 \\
\hline Other & $-1.72 * * *$ & 0.34 & 0.18 & 0.03 & 0.35 & $-1.72 * * *$ & 0.35 & 0.18 & 0.09 & 0.35 \\
\hline Age & $0.19 * *$ & 0.07 & 1.21 & 1.06 & 1.39 & $0.18^{*}$ & 0.07 & 1.19 & 1.04 & 1.36 \\
\hline Racial/Ethnic Minority $^{\mathrm{c}}$ & 0.44 & 0.28 & 1.55 & 0.89 & 2.70 & 0.44 & 0.29 & 1.55 & 0.88 & 2.74 \\
\hline Urban $^{\mathrm{d}}$ & $0.45^{\dagger}$ & 0.25 & 1.56 & 0.95 & 2.56 & 0.39 & 0.25 & 1.47 & 0.89 & 2.43 \\
\hline Stress & $0.27 *$ & 0.12 & 1.31 & 1.04 & 1.64 & $0.26^{*}$ & 0.12 & 1.29 & 1.02 & 1.64 \\
\hline $\begin{array}{l}\text { Discrimination } \\
\text { (30 days) }\end{array}$ & 0.01 & 0.08 & 1.01 & 0.87 & 1.17 & 0.03 & 0.08 & 1.03 & 0.88 & 1.19 \\
\hline \multicolumn{11}{|l|}{ LGBT community } \\
\hline Connectedness & $-0.40 *$ & 0.17 & 0.67 & 0.48 & 0.93 & $-0.34^{*}$ & 0.17 & 0.71 & 0.51 & 0.99 \\
\hline $\begin{array}{c}\text { Organizational } \\
\text { membership }\end{array}$ & $0.51 *$ & 0.21 & 1.67 & 1.11 & 2.49 & $0.38^{\dagger}$ & 0.21 & 1.46 & 0.96 & 2.22 \\
\hline Social participation & 0.06 & 0.15 & 1.06 & 0.79 & 1.42 & 0.09 & 0.15 & 1.09 & 0.81 & 1.48 \\
\hline \multicolumn{11}{|l|}{ Social networks } \\
\hline Peer support & & & & & & $-0.26^{*}$ & 0.13 & 0.77 & 0.60 & 0.99 \\
\hline $\begin{array}{l}\text { Friends of same } \\
\text { identity }\end{array}$ & & & & & & $0.31^{\dagger}$ & 0.18 & 1.36 & 0.96 & 1.92 \\
\hline Time with SSA women & & & & & & -0.13 & 0.18 & 0.88 & 0.62 & 1.24 \\
\hline LR chi 2 & & & & $78.92 * * *$ & & & & & & $86.23 * * *$ \\
\hline Pseudo R2 & & & & 0.1534 & & & & & & 0.1676 \\
\hline
\end{tabular}

everyday smoker as compared to a some days smoker was observed, and neither connection to the LGBT community nor social participation was predictive of frequency of smoking. For full results, see Model 1 in Table 3.

\section{Heavy Smokers ( $\geq 5$ cigarettes per day) Versus Light Smokers $(<5$ cigarettes per day)}

Among smokers $(n=360)$, connection to the LGBT community was associated with the amount of cigarettes consumed. On average, a one point increase on the LGBT community inclusion item was associated with a $39 \%$ reduced odds of being a heavy smoker as a compared to being a light smoker. None of the other LGBT community items were significantly related to the amount of cigarettes consumed by smokers. For full results, see Model 1 in Table 4.
Social Network Characteristics, LGBT Community

Participation, and Smoking Behaviors

\section{Smokers Versus Nonsmokers}

Adding social network characteristics to the model (see Model 2 in Table 3) revealed some important relationships. High levels of peer support were protective-a one standard deviation increase in social support from peers was associated with a $23 \%$ decreased odds of being a smoker as compared to a nonsmoker. A marginal effect of friends of the same identity and smoking status was detected, and time with same sex attracted women was not associated with smoking status. With the introduction of the social network characteristics, the magnitude of the relationship between connection to the LGBT community and smoking was reduced: for every one point increase on the connectedness item, there was a $29 \%$ decrease in the odds of 
Table 3 Everyday smokers versus some days $\operatorname{smokers}^{\mathrm{a}}(\mathrm{n}=360)$

\begin{tabular}{|c|c|c|c|c|c|c|c|c|c|c|}
\hline & \multicolumn{5}{|l|}{ Model 1} & \multicolumn{5}{|l|}{ Model 2} \\
\hline & Coefficient & $\begin{array}{l}\text { Standard } \\
\text { Error }\end{array}$ & $\begin{array}{l}\text { Odds } \\
\text { Ratio }\end{array}$ & $\begin{array}{l}\text { OR } \\
95 \%\end{array}$ & $\mathrm{CI}$ & Coefficient & $\begin{array}{l}\text { Standard } \\
\text { Error }\end{array}$ & $\begin{array}{l}\text { Odds } \\
\text { Ratio }\end{array}$ & OR $95 \%$ & $\mathrm{CI}$ \\
\hline \multicolumn{11}{|l|}{ Sexual identity ${ }^{b}$} \\
\hline Bisexual & 0.40 & 0.28 & 1.49 & 0.86 & 2.58 & 0.35 & 0.29 & 1.42 & 0.81 & 2.51 \\
\hline Other & $0.84^{\dagger}$ & 0.49 & 2.31 & 0.89 & 6.03 & $0.89^{\dagger}$ & 0.51 & 2.44 & 0.90 & 6.61 \\
\hline Age & $0.19 *$ & 0.08 & 1.20 & 1.04 & 1.40 & $0.25^{* *}$ & 0.08 & 1.29 & 1.09 & 1.51 \\
\hline Racial/Ethnic Minority ${ }^{c}$ & -0.04 & 0.26 & 0.96 & 0.57 & 1.60 & -0.03 & 0.27 & 0.97 & 0.57 & 1.65 \\
\hline Urban $^{\mathrm{d}}$ & -0.23 & 0.26 & 0.79 & 0.48 & 1.32 & -0.22 & 0.26 & 0.80 & 0.48 & 1.35 \\
\hline Stress & -0.02 & 0.13 & 0.98 & 0.76 & 1.27 & -0.01 & 0.13 & 0.99 & 0.76 & 1.28 \\
\hline Discrimination (30 Days) & $0.26 * *$ & 0.09 & 1.29 & 1.08 & 1.54 & $0.24 * *$ & 0.09 & 1.27 & 1.06 & 1.52 \\
\hline \multicolumn{11}{|l|}{ LGBT community } \\
\hline Connectedness & -0.07 & 0.19 & 0.93 & 0.64 & 1.36 & -0.15 & 0.21 & 0.86 & 0.58 & 1.29 \\
\hline $\begin{array}{l}\text { Organizational } \\
\text { membership }\end{array}$ & $-0.38^{\dagger}$ & 0.21 & 0.68 & 0.45 & 1.03 & -0.21 & 0.22 & 0.81 & 0.53 & 1.26 \\
\hline $\begin{array}{l}\text { Social participation } \\
\text { scale }\end{array}$ & 0.02 & 0.17 & 1.02 & 0.74 & 1.42 & -0.03 & 0.17 & 0.97 & 0.69 & 1.36 \\
\hline \multicolumn{11}{|l|}{ Social networks } \\
\hline Peer support & & & & & & $0.37 * *$ & 0.14 & 1.45 & 1.10 & 1.93 \\
\hline Friends of Same Identity & & & & & & $-0.38^{*}$ & 0.18 & 0.68 & 0.48 & 0.97 \\
\hline $\begin{array}{l}\text { Time spent with SSA } \\
\text { women }\end{array}$ & & & & & & 0.29 & 0.19 & 1.33 & 0.90 & 1.96 \\
\hline LR chi2 & & & & \multicolumn{5}{|c|}{$34.81 * * *$} & \multicolumn{2}{|l|}{$47.74 * * *$} \\
\hline Pseudo R2 & & & & \multicolumn{5}{|c|}{0.0762} & \multicolumn{2}{|l|}{0.1045} \\
\hline
\end{tabular}

${ }^{a}$ Some days served as referent group

${ }^{\mathrm{b}}$ Lesbians serve as referent group

c White/European American women serve as referent group

${ }^{\mathrm{d}}$ Women who reported living in suburban or rural environments served as referent group

${ }^{\dagger} p \leq 0.1, * p \leq 0.05, * * p \leq 0.01, * * * p \leq 0.001$

being a smoker as compared to a nonsmoker; however, the relationship remained significant. On the other hand, the association between organizational membership and smoking status became only marginally significant.

\section{Everyday Smokers Versus Some Days Smokers}

Social network characteristics were predictive of the frequency of smoking among smokers (see Table 3). High levels of peer support were linked with an increased likelihood of being an everyday smoker as compared to a some days smoker. A one standard deviation increase in peer support was associated with 1.45 odds increase of being an every day smoker. In the other direction, having more friends of the same sexual identity reduced the likelihood of being an everyday smoker as compared to a some days smoker. On average, a one point increase on the friends of the same sexual identity item was associated with $32 \%$ reduced odds of being an everyday smoker. We did not observe a relationship between time spent with same sex attracted women and smoking frequency. No LGBT community participation variables were significant in this model.

\section{Heavy Smokers ( $\geq 5$ cigarettes per day) Versus Light Smokers $(<5$ cigarettes per day)}

In this analysis, we observed that women who had more friends of their same sexual identity were less likely to smoke five or more cigarettes a day (see Model 2 in Table 4). A one point increase on the friends of the same sexual identity item was associated with a $47 \%$ reduced odds of being a heavy smoker as compared to a light smoker. Neither peer support nor time spent with same sex attracted women had any observed relationship to amount. The relationship between connection to the local LGBT community and smoking amount continued to be strong in Model 2: a one point increase in feelings of connectedness 
Table 4 Heavy smokers versus Light smokers ${ }^{\mathrm{a}}(\mathrm{n}=360)$

\begin{tabular}{|c|c|c|c|c|c|c|c|c|c|c|}
\hline \multirow[t]{2}{*}{ Variable } & \multicolumn{5}{|l|}{ Model 1} & \multicolumn{5}{|l|}{ Model 2} \\
\hline & Coefficient & $\begin{array}{l}\text { Standard } \\
\text { error }\end{array}$ & $\begin{array}{l}\text { Odds } \\
\text { ratio }\end{array}$ & $\begin{array}{l}\text { OR } \\
95 \%\end{array}$ & $\mathrm{CI}$ & Coefficient & $\begin{array}{l}\text { Standard } \\
\text { error }\end{array}$ & $\begin{array}{l}\text { Odds } \\
\text { ratio }\end{array}$ & $\begin{array}{l}\text { OR } \\
95 \%\end{array}$ & $\mathrm{CI}$ \\
\hline \multicolumn{11}{|l|}{ Sexual identity ${ }^{\mathrm{b}}$} \\
\hline Bisexual & -0.06 & 0.31 & 0.94 & 0.51 & 1.73 & -0.06 & 0.32 & 0.91 & 0.51 & 1.75 \\
\hline Other & -0.57 & 0.52 & 0.57 & 0.20 & 1.59 & -0.51 & 0.54 & 0.60 & 0.21 & 1.71 \\
\hline Age & $0.23 * *$ & 0.08 & 1.26 & 1.07 & 1.47 & $0.27 * * *$ & 0.08 & 1.31 & 1.11 & 1.54 \\
\hline Racial/Ethnic Minority $^{\mathrm{c}}$ & -0.09 & 0.28 & 0.91 & 0.53 & 1.58 & -0.25 & 0.29 & 0.78 & 0.44 & 1.38 \\
\hline Urban $^{\mathrm{d}}$ & -0.20 & 0.28 & 0.82 & 0.47 & 1.43 & -0.19 & 0.29 & 0.82 & 0.46 & 1.46 \\
\hline Stress & 0.02 & 0.14 & 1.02 & 0.77 & 1.35 & 0.02 & 0.14 & 1.02 & 0.77 & 1.35 \\
\hline Discrimination (30 days) & 0.14 & 0.10 & 1.15 & 0.94 & 1.40 & 0.15 & 0.10 & 1.17 & 0.96 & 1.42 \\
\hline \multicolumn{11}{|l|}{ LGBT community } \\
\hline Connectedness & $-0.49 *$ & 0.20 & 0.61 & 0.42 & 0.91 & $-0.45^{* *}$ & 0.22 & 0.64 & 0.42 & 0.98 \\
\hline $\begin{array}{l}\text { Organizational } \\
\text { Membership }\end{array}$ & 0.18 & 0.23 & 1.20 & 0.77 & 1.87 & 0.14 & 0.25 & 1.15 & 0.71 & 1.88 \\
\hline $\begin{array}{l}\text { Social participation } \\
\text { Scale }\end{array}$ & 0.17 & 0.18 & 1.18 & 0.82 & 1.69 & 0.13 & 0.19 & 1.14 & 0.78 & 1.64 \\
\hline \multicolumn{11}{|l|}{ Social networks } \\
\hline Peer support & & & & & & -0.11 & 0.16 & 0.90 & 0.65 & 1.23 \\
\hline $\begin{array}{l}\text { Friends of same } \\
\text { identity }\end{array}$ & & & & & & $-0.64 * * *$ & 0.19 & 0.53 & 0.36 & 0.77 \\
\hline $\begin{array}{l}\text { Time with SSA } \\
\text { women }\end{array}$ & & & & & & 0.40 & 0.22 & 1.49 & 0.97 & 2.29 \\
\hline LR chi2 & & & & 16.66 & & & & & $29.08 * *$ & \\
\hline Pseudo R2 & & & & 0.0426 & & & & & 0.0743 & \\
\hline
\end{tabular}

${ }^{a}$ Light smokers served as referent group

${ }^{\mathrm{b}}$ Lesbians serve as referent group

c White/European American women serve as referent group

${ }^{\mathrm{d}}$ Women who reported living in suburban or rural environments served as referent group

${ }^{\dagger} p \leq 0.1, * p \leq 0.05, * * p \leq 0.01, * * * p \leq 0.001$

was associated with a $36 \%$ reduced odds of being a heavy smoker as compared to a light smoker.

\section{Discussion}

In this study, we examined the relationship between LGBT community ties, social network characteristics, stress, and smoking among young sexual minority women. Overall, our study provided support for the conceptualization of LGBT community connection as protective against smoking and highlighted the importance of strong social ties for YSMW; however, our findings also underscore the importance of differentiating between psychological connection and participation in evaluating these relationships. We believe our results legitimize the inclusion and incorporation of LGBT community and sexuality-specific social network ties in intervention work with YSMW. We elaborate on the results and their implications below.
With regards to risk of smoking for sexual minority women, our study provided evidence that the LGBT community plays a protective role for young women. Participants who expressed a higher degree of connection to the LGBT community smoked less frequently than those who expressed a lower degree of connection to the LGBT community. Our finding about smoking status echoes the work of Kertzner et al. (2009) who found that LGBT community connectedness was linked to greater sense of social and psychological well being. Conversely, young women involved in more LGBT organizations had increased odds of being a smoker, but this association disappeared when we accounted for the protective effects of social support. This finding may reflect the use of smoking as a strategy to create connections with other sexual minorities (National LGBTQ Young Adult Tobacco Project 2010), particularly if meeting peers within LGBT organizations where YSMW are more likely to smoke. Similarly, these results may be an artifact of the trajectory discovered by Rosario and colleagues (2004), 
where use of substances increased when first participating in LGBT activities, while continued participation was associated with decrease in use over time. Potentially, those who reported more organizational memberships may be earlier on in their coming out process than those who reported high feelings of community connection. This interpretation is further supported by the fact that the risks associated with organizational membership were mitigated by the inclusion of peer support in the model. Taken together, our results suggest fostering psychological connections to LGBT community and peers have an important role to play in reducing the smoking of sexual minority women. At present, however, it remains unclear whether peer social support stemmed from YSMW's increased participation in the LGBT community. Future longitudinal research examining whether LGBT community participation increases YSMW's access to social support and, in turn, reduces the likelihood of smoking is warranted.

We were also interested in studying the behaviors of smokers to disentangle the ways in which community and social network properties related to the frequency and amount of smoking among YSMW. With regard to smoking frequency (i.e., did YSMW smokers smoke every day or only some days), we found that being a member of more LGBT organizations decreased women's odds of being an everyday smoker. Notably, this effect disappeared when we entered social network characteristics (e.g., perceived interactional and functional properties) into the model. We found high levels of peer support to be associated with greater odds of being an everyday smoker. This pattern may point to the difference between frequent and infrequent smokers. As (Okuyemi et al. 2002) note, heavy smokers and light smokers differ in their motivations for smoking, with light smokers being more likely to smoke for social reasons. Our findings that everyday smokers had high levels of peer support (and thus that some days smokers have lower levels of peer support) is consistent with the idea that frequent smokers do not smoke to forge social connections, while infrequent smokers may be using cigarettes as a social tool that helps to forge new social connections. Conversely, having friends who were the same sexual identity decreased the odds of being an everyday smoker. Given that experiences of discrimination (minority stress) were strongly associated with being an everyday smoker, we believe one interpretation of these results could be that YSMW in the everyday smoker category smoke to contend with minority stress and do not have sufficient identity support to buffer this strain. Thus, when intervening on the issue of smoking among YSMW, practitioners must be clear about what type of smoker they are targeting (everyday or some days), as this will direct whether social relationships need to be center of the intervention platform or not.
Our final set of analyses examined the amount of cigarettes consumed by YSMW smokers (i.e., did they smoke less than 5 cigarettes a day or more than 5 cigarettes a day). We found that YSMW smokers with a greater feeling of connectedness to a local LGBT community consumed fewer cigarettes than women with less connection to the LGBT community. By adding social network characteristics to the model, we found that YSMW smokers with more friends of their same sexual identity consumed fewer cigarettes than those with fewer friends of the same sexual identity. Thus, our results paint a fairly straightforward story of the protective association between LGBT community connections, friends, and smoking. This trend compliments (Doty et al. 2010) discovery that having more sexuality related social support was linked to lower levels of emotional distress among sexual minority youth. Since smoking is often cited as a coping mechanism for sexual minority stress (Gruskin et al. 2008), YSMW with strong ties to other sexual minority women may need fewer cigarettes, less often. Alternatively, this finding may again highlight the difference between heavy and light smokers (Okuyemi et al. 2002), in that women who are consuming fewer cigarettes are doing so in order to bolster community connections, which is why they score higher on assessments of LGBT community connectedness and having friends of the same identity. Unfortunately, our data did not allow for an analysis of the density of smokers or the patterns of smoking within these friends of the same identity, which would be useful information to obtain in order to continue dissecting the role of peer influence in the context of YSMW's smoking behaviors. Future research is needed to examine the structure of these relationships cross-sectionally and over time in order to determine the influence of LGBT community connections and smoking behaviors.

Finally, our stepwise modeling procedure allowed us to investigate whether the construct of LGBT community had meaningful relationships to smoking for YSMW, or whether the health protective benefits of connections to other sexual minorities could best be understood in relation to their social network characteristics. This distinction is important given that sexual minority women may not as readily identify with the LGBT community as sexual minority men (Ferris 2006; Ward 2008). Consistently, as we added social network characteristics to the models, we found that the relationships of LGBT community to smoking behaviors were attenuated by social network characteristics, but did not disappear altogether. This finding indicates that YSMW may find support and meaning in LGBT community above and beyond their interpersonal friendships with other YSMW. This trend is notable, for despite conversations about the LGBT community's inaccessibility to women (Ward 2008), YSMW 
still appear to benefit from a sense of inclusion in this broader cultural group. Furthermore, these findings point to a potential mediation pathway between LGBT community connections and smoking behaviors through YSMW's social network characteristics. Given the cross-sectional nature of our data, however, we are unable to test this causal assumption, and believe that further inquiry into these relationships would be useful.

\section{Strengths and Limitations}

While this study contributes to the understanding of the relationship between YSMW's social connections and their smoking behaviors, our study contains a few limitations. Because our dataset is cross sectional, we are unable to test causal pathways around smoking behaviors and cannot assess how smoking behaviors shift as YSMW interact with the community and their peers over time; however, we were able to examine smoking behaviors in a multidimensional manner, separating out smoking status, frequency of smoking, and smoking amount in our analysis, thus expanding our understanding of the profiles of YSMW who smoke. Additionally, our current survey relied on selfreport data on the smoking behaviors of YSMW. Self report data may underestimate cigarette use among youth (Patrick et al., 1994); however this methodology is consistent with other research studies on tobacco among SMW. Moving forward, research in this area may wish to include biomarkers of smoking to fine tune the understanding of smoking patterns and nicotine dependence as important factors in smoking patterns of YSMW. Furthermore, we utilized a web-based, convenience sampling strategy, and thus our findings are not generalizable to the whole of YSMW; however, we believe that the insights into the relationships between LGBT community, social network characteristics, and smoking in our sample provide invaluable foundational information into this health disparity. Finally, due to data constraints, we were unable to evaluate the structural properties of YSMW's social networks through methodologies such as egocentric network analysis, nor were we able to account for more proximal influences on YSMW's smoking behaviors such as partners, friends, and families. Before developing smoking interventions specific to YSMW, these lines of inquiry may need to be addressed, and we believe this study provides an important first step in defining future formative research.

These limitations notwithstanding, our study contains several notable strengths. First, few studies have been done explicitly examining the smoking behaviors of YSMW. With this focus, we were able to ask important and novel questions about the social relationships that may undergird smoking behaviors among YSMW. Second, we included several different measurements of community (e.g., connection, participation) and social network properties (e.g., support, friends of same identity), and were able to gain a more nuanced understanding of the ways in which women's communities of identity may relate to their smoking behaviors. Furthermore, due to our web recruitment strategy, we were able to enroll a geographically diverse sample of women, residing in urban, suburban, and rural areas. This diversity may have allowed for a wider snapshot of YSMW, particularly in terms of their relationship to the LGBT community, as other studies that rely on LGBT community venues for recruitment may oversample those with strong community ties. Finally, our sample focused specifically on youth, rather than LGB adults more broadly. This focus allowed us to examine the role of social relationships in young women's lives at an important development moment in which they are both at heightened risk for beginning smoking (Marshal et al. 2012) and may be exploring their sexual identities (SavinWilliams 2011).

\section{Implications for Research and Intervention}

The results of this study provide insight into how to move forward on the issue of smoking prevention among YSMW. While previous literature has produced mixed results regarding whether LGBT community ties are health promotive or risky (Frost and Meyer 2012; National LGBTQ Young Adult Tobacco Project 2010; RamirezValles 2002; Stevens et al. 2004), our findings support the view that building connections to the LGBT community is beneficial to the health and well-being of YSMW, as psychological connection to the community was continuously related to less smoking. Given that our analyses came out of cross-sectional data, further longitudinal research would be useful to examine smoking trajectories among YSMW, and specifically detail how women's LGBT community and social network ties predict the ways in which women use tobacco over time. In relation to intervention development, our research supports consideration of how to incorporate the LGBT community building when designing anti-tobacco interventions for YSMW. For example, given the protective benefits of feeling connected to the community and having other similarly identified friends, interventions may want to bolster the ties that YSMW have to one another, perhaps by the creation of community spaces or events that are targeted explicitly for sexual minority women. Furthermore, given that YSMW do appear to be engaging LGBT organizations, interventionists may benefit from tapping into preexisting social networks to disseminate anti-smoking programming and messages. By disaggregating smoking status into frequency and amount, our study lends credence to the perspective 
that light and heavy smokers have different relationships to cigarettes, and thus interventions should distinguish between these two groups with regard to the prioritization of community building. Overall, we believe LGBT community and social relationships are a critical explanatory component of YSMW's health behaviors, and interventionists who seek to design programs that are meaningful in YSMW's lives should strive to address these domains.

\section{References}

Austin, S. B., Ziyadeh, N., Fisher, L. B., Kahn, J. A., Colditz, G. A., $\&$ Frazier, A. L. (2004). Sexual orientation and tobacco use in a cohort study of US adolescent girls and boys. Archives of Pediatrics and Adolescent Medicine, 158(4), 317-322.

Bauermeister, J. A. (2012). Romantic ideation, partner-seeking, and HIV risk among young men who have sex with men. Archives of Sexual Behavior, 41(2), 431-440.

Bauermeister, J. A., Johns, M. M., Sandfort, T. G. M., Eisenberg, A., Grossman, A. H., \& D'Augelli, A. R. (2010). Relationship trajectories and psychological well-being among sexual minority youth. Journal of Youth and Adolescence, 39(10), 1148-1163.

Bauermeister, J., Pingel, E., Zimmerman, M., Couper, M., CarballoDiéguez, A., \& Strecher, V. J. (2012). Data quality in web-based HIV/AIDS research: Handling invalid and suspicious data. Field Methods, 24(3), 272-291.

Beals, K. P., \& Peplau, L. A. (2005). Identity support, identity devaluation, and well-being among lesbians. Psychology of Women Quarterly, 29(2), 140-148.

Bergen, A. W., \& Caporaso, N. (1999). Cigarette smoking. Journal of the National Cancer Institute, 91(16), 1365-1375.

Blosnich, J., Jarrett, T., \& Horn, K. (2010). Disparities in smoking and acute respiratory illnesses among sexual minority young adults. Lung, 188(5), 401-407.

Blosnich, J. R., Jarrett, T., \& Horn, K. (2011). Racial and ethnic differences in current use of cigarettes, cigars, and hookahs among lesbian, gay, and bisexual young adults. Nicotine \& Tobacco Research: Official Journal of the Society for Research on Nicotine and Tobacco, 13(6), 487-491.

Brewster, K. L., \& Tillman, K. H. (2012). Sexual orientation and substance use among adolescents and young adults. American Journal of Public Health, 102(6), 1168-1176.

Brown, J. P., \& Tracy, J. K. (2008). Lesbians and cancer: An overlooked health disparity. Cancer Causes and Control, 19, 1009-1020.

Centers for Disease Control and Prevention (CDC). (2012). Smoking and Tobacco Use: Health Effects of Cigarette Smoking. Retrieved from http://www.cdc.gov/tobacco/data_statistics/fact_sheets/ health_effects/effects_cig_smokin g/index.htm.

Christakis, N. A., \& Fowler, J. H. (2008). The collective dynamics of smoking in a large social network. New England Journal of Medicine, 358(21), 2249-2258.

Cohen, S., Kamarck, T., \& Mermelstein, R. (1983). A global measure of perceived stress. Journal of Health and Social Behavior, 24(4), 385-396.

Doty, N., Willoughby, B., Lindahl, K., \& Malik, N. (2010). Sexuality related social support among lesbian, gay, and bisexual youth. Journal of Youth and Adolescence, 39(10), 1134-1147.

Ferris, J. L (2006) The nomenclature of the community: An activist's perspective. The Handbook of Lesbian, Gay, Bisexual, And Transgender Public Health: A Practitioner's Guide to Service Binghamton, NY: The Haworth Press, Inc. pp. 3-10.
Frost, D. M., \& Meyer, I. H. (2012). Measuring community connectedness among diverse sexual minority populations. Journal of Sex Research, 49(1), 36-49.

Gruskin, E. P., Byrne, K. M., Altschuler, A., \& Dibble, S. L. (2008). Smoking it all away: influences of stress, negative emotions, and stigma on lesbian tobacco use. Journal of LGBT Health Research, 4(4), 167-179. doi:10.1080/15574090903141104.

Hatzenbuehler, M. L., Wieringa, N. F., \& Keyes, K. M. (2011). Community-level determinants of tobacco use disparities in lesbian, gay, and bisexual youth: Results from a populationbased study. Archives of Pediatrics and Adolescent Medicine, 165(6), 527-532.

Heaney, C. A., \& Israel, B. A. (2002). Social networks and social support. In K. Glanz, B. K. Rimer, \& F. M. Lewis (Eds.), Health behavior and health education: Theory, Research, and Practice (3rd ed., pp. 185-209). San Francisco, CA: Jossey Bass.

Kertzner, R. M., Meyer, I. H., Frost, D. M., \& Stirratt, M. J. (2009). Social and psychological well-being in lesbians, gay men, and bisexuals: The effects of race, gender, age, and sexual identity. American Journal of Orthopsychiatry, 79(4), 500-510.

Lehavot, K., Balsam, K. F., \& Ibrahim-Wells, G. D. (2009). Redefining the American quilt: Definitions and experiences of community among ethnically diverse lesbian and bisexual women. Journal of Community Psychology, 37(4), 439-458.

Marshal, M. P., Friedman, M. S., Stall, R., \& Thompson, A. L. (2009). Individual trajectories of substance use in lesbian, gay and bisexual youth and heterosexual youth. Addiction, 104(6), 974-981.

Marshal, M. P., King, K. M., Stepp, S. D., Hipwell, A., Smith, H., Chung, T., et al. (2012). Trajectories of alcohol and cigarette use among sexual minority and heterosexual girls. Journal of Adolescent Health, 50(1), 97-99.

Meyer, I. H. (2003). Prejudice, social stress, and mental health in lesbian, gay, and bisexual populations: conceptual issues and research evidence. Psychological Bulletin, 129(5), 674-697.

Meyer, I. H., Frost, D. M., Narvaez, R., and Dietrich, J. H. (2006). Project Stride Methodology and Technical Notes. Retrieved from http://www.columbia.edu/ im15/method/stridemethod.pdf.

National LGBTQ Young Adult Tobacco Project. (2010). Coming Out about Smoking. Retrieved from http://lgbttobacco.org/files/ Coming_Out_About_Smoking_NYAC.pdf.

Nuttbrock, L., Rosenblum, A., and Blumenstein, R. (2002). Transgender identity affirmation and mental health. International Journal of Transgenderism, 6. Retrieved from http://www. symposion.com/ijt/index.htm.

Okuyemi, K., Harris, K. J., Scheibmeir, M., Choi, W., Powell, J., \& Ahluwalia, J. (2002). Light smokers: Issues and recommendations. Nicotine and Tobacco Research, 4(4), 103-112.

Pingel, E., Youatt, E., Johns, M., \& Bauermeister, J. A. (2012). Tobacco use among young lesbian, bisexual and queer-identified women: Considering the "community" in designing interventions and smoking cessation programs. Poster presented at the 2012 American Public Health Association Meeting, San Francisco, CA (October 30).

Pizacani, B. A., Rohde, K., Bushore, C., Stark, M. J., Maher, J. E., Dilley, J. A., et al. (2009). Smoking-related knowledge, attitudes and behaviors in the lesbian, gay and bisexual community: A population-based study from the U.S. Pacific Northwest. Preventive Medicine, 48(6), 555-561.

Procidano, M. E., \& Heller, K. (1983). Measures of perceived social support from friends and from family: Three validation studies. American Journal of Community Psychology, 11, 1-24.

Ramirez-Valles, J. (2002). The protective effects of community involvement for HIV risk behavior: A conceptual framework. Health Education Research, 17(4), 389-403.

Rosario, M. (2008). Elevated substance use among lesbian and bisexual women: Possible explanations and intervention implications for an 
urgent public health concern. Substance Use and Misuse, 43(8-9), $1268-1270$.

Rosario, M., Hunter, J., Maguen, S., \& Gwadz, M. (2001). The coming out process and its adaptational and health-related associations among gay, lesbian, and bisexual youths: Stipulation and exploration of a model. American Journal of Community Psychology, 29(1), 133-160.

Rosario, M., Schrimshaw, E. W., \& Hunter, J. (2011). Cigarette smoking as a coping strategy: Negative implications for subsequent psychological distress among lesbian, gay, and bisexual youths. Journal of Pediatric Psychology, 36(7), 731-742.

Savin-Williams, R. C. (2011). Identity development among sexualminority youth. In S. J. Schwartz, K. Luyckx, \& V. L. Vignoles (Eds.), Handbook of identity theory and research (pp. 671-689). New York, NY: Springer New York.

Shiffman, S. (1989). Tobacco "chippers"-individual differences in tobacco dependence. Psychopharmacology (Berl), 97, 539-547.

Stevens, P., Carlson, L. M., \& Hinman, J. M. (2004). An analysis of tobacco industry marketing to lesbian, gay, bisexual, and transgender (LGBT) populations: Strategies for mainstream tobacco control and prevention. Health Promotion Practice, 5 (3 suppl), 129S-134S.

Tang, H., Greenwood, G. L., Cowling, D. W., Lloyd, J. C., Roeseler, A. G., \& Bal, D. G. (2004). Cigarette smoking among lesbians, gays, and bisexuals: How serious a problem? Cancer Causes and Control, 15(8), 797-803.

Ward, J. (2008). Respectably Queer: Diversity Culture in LGBT activist organizations. Nashville, Tennessee: Vanderbilt University Press.

Wellman, R. J., DiFranza, J. R., \& Wood, C. (2006). Tobacco chippers report diminished autonomy over smoking. Addictive Behaviors, 31(4), 717-721.

Youatt, E., Pingel, E., Johns, M. M., \& Bauermeister, J. A. (2012). Sexual minority females' attitudes toward targeted smoking cessation programs. Poster presented at the 2012 Society for Research on Nicotine and Tobacco (SRNT) Annual Meeting, Houston, Texas (March 16). 